\title{
The impact of Web 2.0 tools on academic libraries in Kenya
}

\author{
Fred Gochi Gichora* and Tom Kwanya \\ Department of Information and Knowledge Management, the Technical University of Kenya.
}

Received 10 November, 2014; Accepted 04 February, 2015

\begin{abstract}
Web 2.0, the read/write social web, has become ubiquitous in most academic libraries, even in developing countries. The use of Web 2.0 tools is increasingly changing the way academic library users seek, access, use, or share information. Thus, the use of Web 2.0 has the potential of impacting the efficiency and effectiveness of service design and delivery in academic libraries the world over. This study explored the impact of Web 2.0 on the effectiveness of service delivery in academic libraries in Kenya. Data for the study were collected through an analytical survey of the web platforms of nine academic libraries in Kenya. The libraries were selected through information-oriented purposive sampling. Additional data were obtained from key informant interviews with librarians and users in two academic libraries also purposively selected from the nine. Secondary data were also collected through documentary analysis of relevant literature. The findings of the study reveal that the use of Web 2.0 tools in academic libraries in Kenya has increased the users' interests in the library resources and services; promoted learning; as well as enriched library promotion and marketing programmes. The findings also revealed that the effective use of Web 2.0 tools in academic libraries in Kenya is hampered by infrastructural, technical, technological and cultural challenges, among other factors, which require urgent attention to enhance their impact. The findings of this study can be used to justify investments in Web 2.0 platforms by academic libraries. They can also be used by library schools to develop curricula which empower librarians to make optimal use of Web 2.0 and similar tools.
\end{abstract}

Key words: Web 2.0, academic libraries, Kenya.

\section{INTRODUCTION}

The last three decades have witnessed unprecedented changes in the way academic libraries conceive and deliver information services. These changes have been largely influenced by the opportunities for better information cycle management through the use of Information and Communication Technologies (ICTs) which are progressively becoming ubiquitous even in developing economies. Consequently, library users expect and are becoming more dependent on web-based information resources. The preference for web-based information resources and services is attributed to their ease of accessibility and use (Hangsing and Sinate, 2012). The situation is not different in Kenya where academic libraries have increasingly adopted diverse Web 2.0 tools

\section{*C orresp onding a uthor. E-mail: gichorafred @gma il.com.}

Author(s) agree that this article remain permanently open access under the terms of the Creative Commons Attribution Lic ense 4.0 Intemational Lic ense. 
to enhance the effectiveness of their services.

The history of academic libraries in Kenya is fairly recent. It can be traced back to the 1940s and is closely tied to the development of academic institutions in the pre-independent Kenya. It is not surprising, therefore, that there were few academic libraries during this period. Some of the earliest academic institutions in this era included Egerton College (now Egerton University) which was established in 1940; the Royal Technical College (now the University of Nairobi) which was established in 1951; and the Kenya Polytechnic (now The Technical University of Kenya) which was established in 1961. These three institutions had well equipped libraries which were then managed by British expatriates (Kimani, 1982). Later in the post-independence Kenya, more institutions of higher learning and academic libraries were established (Otike, 2004). Currently, there are more than 36 institutions of higher learning in the country and they all have academic libraries (CUE, 2014). According to the National Center for Education Statistics (NCES) Academic Library Survey (2010), an academic library is the library associated with a degree-granting institution of higher education. Academic libraries are identified by the post-secondary institution of which they are a part and have the following resources:

1. An organized collection of printed or other materials or a combination thereof;

2. A staff trained to provide and interpret such materials as required to meet the informational, cultural, recreational, or educational needs of clientele;

3. An established schedule through which services of the staff are available to clientele; and

4. The physical facilities necessary to support such a collection and schedule of services.

Academic libraries provide specialised information facilities where exhaustive investigation on a particular field is carried out (Gunasekara, 2005). To achieve this, academic libraries collect information on their areas of interest in greater depth than any other library (Kent et al., 1978). Thus, academic libraries typically hold, or provide access to, both primary and secondary information resources and data which include monographs, conference proceedings, journals, technical reports, and standards, among others. Traue (2009) asserts that the purpose of an academic library is to enable its users to immerse themselves in the available documentary evidence and then to make the product of their investment of time, judgment and skill available to their communities through a book, article, thesis, film, television (TV) production, website or blog. Thus, academic libraries have a unique mandate which their users expect them to deliver through innovative information services and resources. The adoption and use of Web 2.0 in academic libraries is an effort to effectively meet the emerging and diversifying needs of their users in an increasingly net- worked infosphere. In Kenya, the Commission for University Education (CUE) has developed a number of standards for academic libraries. One of the critical items in the standards is an emphasis on the need to invest in emerging relevant ICTs to enhance academic libraries' effectiveness in supporting teaching, learning and research in their parent institutions (CUE, 2007).

\section{Web 2.0}

The term Web 2.0 was first coined in 1999 by DiNucci (DiNucci et al., 1999). It was later popularised by O'Reilly Media beginning 2004 at the first Web 2.0 conference in San Francisco (O'Reilly, 2005). The term refers to a perceived second generation of community-driven Web services such as social networking sites, blogs and wikis, among others, which facilitate a more socially connected Web where everyone is able to communicate, participate, collaborate, add to or edit content (Anderson, 2007; Pachler and Daly, 2009). This technology enables its users to go beyond the static web page structures to more interactive co-created platforms. It has brought a dramatic change in the way people use the Internet and offers its users several tools and services that facilitate versatile interaction and participation. As O'Reilly (2005) observed, Web 2.0 has transformed personal web-pages into blogs; encyclopaedia into Wikipedia; text-based tutorials into streaming media applications; taxonomies into folksonomies; and question-answer/e-mail customer support into instant messaging services.

Contrary to what most people perceive it to be, Web 2.0 is not a standard. As O'Reilly (2005) projected, it is just a collection of ideas. Goh et al. (2007) observe that Web 2.0 has recently influenced the structures and features of new information systems and represents an emerging suite of applications that hold immense potential in enriching communication, enabling collaboration and fostering innovation (Alton and Dion, 2010). Therefore, Web 2.0 can play a key role in facilitating effective information sharing, collaboration, and communication among library users, librarians and between librarians and users in academic settings.

McAfee (2006) used the acronym SLATES to represent the Web 2.0 features:

1. $S$ for Search: the ease of finding information through keyword search that makes the platform valuable;

2. L for Links: guides to important pieces of information. The best pages are the most frequently linked to;

3. A for Authoring: the ability to create constantly changing content over a platform that has shifted from being the creation of a few to being the constantly updated, interlinked network. In wikis, for instance, the content is iterative in the sense that the people undo and redo each other's work. In blogs, content and comments of individuals are posted and accumulated over time; 
4. T for -Tags: categorisation of content by creating tags that are simple, one-word descriptions to facilitate easier searching and thus avoid the rigid, pre-made categories;

5. E for Extensions: automation of some of the work and pattern matching by using algorithms; and

6. S for Signals: users are notified about any change in content they are interested in through diverse communication channels.

The emergence of Web 2.0 led to the development of Library 2.0 concept. The term Library 2.0 was first coined by Michael Casey in his blog Library Crunch in September 2005 (Casey and Savastinuk, 2006). Library 2.0 is geared towards making information available wherever and whenever the user requires it and seeks to ensure that barriers to the use and reuse of information are removed or reduced. Thus, Library 2.0 seeks to help libraries achieve their age-old mandate of helping their users to interact with relevant information promptly. Library 2.0 is perceived to have created a second generation of libraries which do not only exemplify a change in technologies but also a paradigm shift towards user-centricity and participation.

\section{Rationale of the study}

Web 2.0 tools are rapidly gaining popularity in all walks of life as they facilitate robust online interaction and collaboration among their users. Academic libraries have not been left behind in this development. Previous studies have revealed how Web 2.0 tools can be and are being used to enhance the design and delivery of effective library services (Bradley, 2007; Huffman, 2006). The Libraries and Social Software in Education (LASSIE) project report (2007) gives an overview of how Web 2.0 tools have influenced the delivery of their services which include increased user generated content in the catalogue, and improved information sharing and communication. The tools have also enabled libraries to involve users in their activities and solicit their feedback for improving the library services and resulted in better usability of academic library resources (Hangsing and Sinate, 2012). Web 2.0 tools have also expanded the scope and depth of library services provided online through library websites and portals.

Makori (2012) argues that many academic libraries in Kenya have already adopted a wide variety of Web 2.0 tools in their websites. Although the adoption of Web 2.0 tools by libraries has attracted many researchers globally, few researchers so far have sought to understand the real impact of the technology on library services, especially in academic libraries (Khalid, 2013). The situation is more serious in Africa where only a few researchers have written on Web 2.0, leave alone its application in libraries (Kebede, 2014). Consequently, there exists a gap in the literature discussing the impact of Web 2.0 technologies in academic libraries in Kenya.
The current study sought to bridge this gap by investigating the Web 2.0 tools adopted by academic libraries in Kenya as well as their impact on the design and delivery of effective services to their user communities. The study specifically sought to identify the Web 2.0 tools applied in academic libraries in Kenya; investigate the purposes for which these Web 2.0 tools are used in the academic libraries in Kenya; evaluate the impacts of using Web 2.0 tools in the academic libraries; and recommend strategies which can be used to enhance the impact of these tools on academic libraries in Kenya.

\section{RESEARCH METHODOLOGY}

Kothari (2007) defines research design as the arrangement of conditions for the collection and analysis of data in a manner that aims to combine relevance to the research purpose with economy in procedure. Cooper and Schindler (2003) also argue that research design is a structure for identifying the relationship among the study variables and sketches out the methodology for every research action. This study used mixed methods of research which encompassed both qualitative and quantitative approaches so as to enrich the data perspectives by compensating for the weaknesses of using either method singly (Neuman, 2006). The researchers conducted an analytical survey of nine academic library websites in Kenya to establish the Web 2.0 tools they used to offer services to their users. In addition, two academic libraries - The Technical University of Kenya and Strathmore University - were selected through information-oriented purposive sampling for further study. The issues covered by the further study included the uses of Web 2.0 tools applied in the libraries as well the impact of using those Web 2.0 tools on the effectiveness of library service delivery.

Data for the extended study were collected through selfadministered questionnaires which were given to four librarians on duty at Strathmore University Library and ten users chosen randomly from those present in the library at the time of data collection. From The Technical University of Kenya, five librarians were issued with the questionnaires; ten users of the library present at the time of data collection were also chosen randomly and issued with the questionnaires. Secondary data on the use of Web 2.0 in academic libraries were collected through documentary analysis of various literature sources. The collected data were analysed through content analysis. Table 1 shows the academic library websites which were surveyed.

\section{FINDINGS AND DISCUSSION}

\section{Web 2.0 tools applied in academic libraries in Kenya}

The study revealed that Really Simple Syndication (RSS), blogs, wikis, instant messenger (IM), podcast, YouTube, LinkedIn, Delicious, and social networking sites like Facebook were the major tools used by academic libraries in Kenya.

RSS was the most popular Web 2.0 technology applied with all academic libraries having adopted it. The high popularity of RSS was due to the fact that it enables librarians and library users to send or receive updates from a single aggregated platform. Its popularity may have also been enhanced by the fact that it requires less 
Table 1. List of university web sites surveyed.

\begin{tabular}{ll}
\hline University & Library website \\
\hline University of Nairobi (UoN) & uonlibrary.uonbi.ac.ke \\
Kenyatta University (KU) & library.ku.ac.ke \\
The Technical University of Kenya (TUK) & library.tukenya.ac.ke \\
Moi University (MU) & mtl.mu.ac.ke \\
Mount Kenya University (MKU) & kevconco.com/ mku/ \\
The Catholic University of Eastern Africa (CUEA) & cuea.edu/gaba/index.php/library \\
University of Eastern Africa Baraton (UEAB) & ueab.academia.edu/departments/library \\
Masinde Muliro University of Science and Technology & library.mmust.ac.ke \\
Maseno University & library.maseno.ac.ke \\
\hline
\end{tabular}

Table 2. List of Web 2.0 academic libraries in Kenya use.

\begin{tabular}{lcc}
\hline Web 2.0 tools & Frequency (out of 10) & Percentage \\
\hline RSS & 10 & 100 \\
Facebook & 8 & 80 \\
Blogs & 7 & 70 \\
Wikis & 7 & 70 \\
Instant & 5 & 50 \\
messenger & & \\
Podcasts & 3 & 30 \\
Delicious & 2 & 20 \\
Twitter & 2 & 20 \\
LinkedIn & 1 & 10 \\
YouTube & 1 & 10 \\
\hline
\end{tabular}

intervention once it has been set up. These findings concur with Imran (2011) who argues that RSS has been one of the most utilised technologies as it enables users to create a one-stop-shop of information.

Facebook ranked second and was used by 80 percent of the academic libraries in Kenya. The popularity of Facebook was due to its powerful social networking and relationship building features as well as its widespread use among university students in Kenya. YouTube emerged as the least applied Web 2.0 tool in academic libraries in Kenya at only 10 percent. The low usage of YouTube can be attributed to the bandwidth limitations most academic libraries in Kenya face. The situation may have also been exacerbated by the fact that most users accessed the Internet using their mobile phones. Table 2 presents the Web 2.0 tools used by academic libraries in Kenya as well as their levels of popularity.

\section{Purposes of the Web 2.0 tools in the academic libraries in Kenya}

This information was obtained through the interviews conducted with the patrons and librarians from the two universities which participated in the extended study:
RSS

Most of the academic libraries used RSS to announce new books in specific fields or subjects, new e-journals, and library news and events. RSS was also used to announce the availability of new research and learning opportunities, for compiling customised alerts, promoting events organised for library users, and providing help for catalogue searches.

\section{Facebook}

Facebook was used by the libraries to create a community with its users where news like new books, articles or events promoted by the library were posted. Facebook was also applied by the users to communicate with librarians for inquiries and in turn receive information on their queries. Also, Facebook was used as a platform through which innovative ideas were shared amongst library users and librarians.

\section{Blogs}

Most academic libraries in Kenya used blogs to provide research tips; present lists of new books, resources and databases; book reviews and discussions; information literacy and user education; informing users about hours of operation and holidays; providing links to the library catalogues; collection development where librarians assessed the users' requests for resources; and for marketing library and information services to their users.

\section{Wiki}

Wikis were used to provide links to guide the users to related pages with additional information. Other uses of wikis were to share information and enhance the content, archiving transactions for future reference, creating subject guides, and providing subject gateways. 


\section{Instant messenger}

Instant messenger was mainly used as a platform for text and or video chat through which advice on library services was offered. Most of the libraries which used this tool applied it to solicit and respond to users' queries; provide current awareness services through alerts; specialized dissemination of information; and engage the users on myriad issues affecting their use of the library services and products.

\section{Podcast}

Podcasts were used to provide advice on library skills, searching library catalogues, guidance to use resources, archiving interviews/speeches of heads of institutions and important library guests, publishing users' and librarians' presentations, and providing virtual library orientation tours.

\section{Delicious}

Delicious was used for tagging. A tag is a keyword that is added to a digital object to describe it. Users used delicious to tag documents as well as choose and add uncontrolled keywords that allowed them to identify library resources better. Furthermore, the use of Delicious enabled the users to share their perceptions of the resources thus helping their peers to identify, access, and use relevant resources easily. However few academic libraries (20\%) applied it as a library management system to edit subject headings using the contributions of the users. Delicious was also used to facilitate effective discovery, storage and sharing of digital information sources.

\section{The impact of Web 2.0 tools on academic libraries}

The top impact of using Web 2.0 tools for academic libraries in Kenya was improved awareness of library resources (86\%). This impact was achieved through the wide application of RSS by the libraries. This impact was further augmented by the versatile social connectedness of users and librarians through Web 2.0 tools such as Twitter, Linkedln and Facebook. The other notable impact was improved communication among librarians and between librarians and patrons (81\%). Web 2.0 has deepened communication amongst library communities due to the fact that the tools are not too formal thus reducing the restrictions associated with traditional communication. The other impacts of Web 2.0 on academic libraries in Kenya included improved searching and exposure to more information materials (77\%); and increased usage of library resources (65\%). The other identified impacts included:
1. Increased interest in the library;

2. Enhanced indexing and search relevance;

3. Improved timeliness of information;

4. Increased efficiency and effectiveness of outreach activities;

5. Increased collaboration and customisation of communication;

6. Increased learning and knowledge sharing;

7. Reduced costs of library operations and training;

8. Improved flexibility of library services because users can access them from anywhere, any time with much ease; and

9. Reduced information overload as users only access what they need and depend on the communities to filter or recommend credible information and sources.

Some negative impacts were also identified. These included reduced confidentiality of information especially in wikis since there was little trace or proof of ownership and authenticity of the authors' skills and knowledge level in those fields they were contributing on. Similarly, there were doubts about the reliability of tools; standardisation challenges; and increased occurrence of insecurity incidents; as well as the emergence of sophisticated legal and moral issues pertaining to the use of Web 2.0 tools in academic libraries. There were also difficulties arising from relying on inadequate infrastructure and technical skills as well as restrictions on access of certain Web 2. 0 tools to certain users. These difficulties hampered the effective use of Web 2.0 tools amongst both librarians and users.

\section{Conclusion}

This study revealed that Web 2.0 tools were widely used in most academic libraries in Kenya. In fact, all the sampled libraries used one or more Web 2.0 tools. It is also evident from the findings that the use of Web 2.0 tools in academic libraries in Kenya has had a positive impact on the effectiveness and efficiency of services they provide. However, academic libraries in Kenya faced myriad challenges in their efforts to use Web 2.0 tools effectively. Some of the challenges included inadequate infrastructure and technical skills amongst librarians and users

\section{RECOMMENDATIONS}

Based on the above findings, the authors recommend that Web 2.0 tools should be used with well-defined purposes and standards to facilitate the participation of users in library activities and improve their confidence in online user-generated information, especially in wikis. Use of wikis relevant to the academic curricula should be encouraged and advocated for all academic libraries to supplement their resources; Web 2.0 tools such as blogs 
Int. J. Lib. Inf. Sci.

targeting unique information needs of specific library user groups should be adopted; the scope of Web 2.0 platforms used by libraries should be limited to avoid scattering users and thus making them less interactive; the use of platforms like YouTube, Google plus and LinkedIn should be encouraged in all libraries to facilitate library exposure to various levels of users for publicity and professional networking as well as communication and sharing of information. In addition, students and faculty members should be trained and encouraged to embrace Web 2.0 tools in order to enhance their confidence in the credibility of the Web 2.0 content; increase the awareness of the tools applied by creating promotional flyers and bookmarks about them; and provide links of Web 2.0 tools from the home pages of the library websites so that users can access them easily.

\section{REFERENCES}

Alton Y, Dion H (2010). A study of Web 2.0 applications in library websites. Libr. Inform. Sci. Res. 32(3):203-211.

Anderson P (2007). What is Web 2.0? Ideas, technologies and implications for education. Available from: http://www.jisc.ac.uk/media/documents/techwatch/tsw0701b.pdf. Accessed 6 November 2014.

Bradley P (2007). How to use Web 2.0 in your library. London: Facet Publishing.

Casey E, Savastinuk L (2006). Library 2.0 services for the next generation libraries. Library Journal. Available from: http://lj.libraryjournal.com/2010/05/technology/library-2-0/\#_. Accessed 6 November 2014.

Commission for University Education (2007). Standards and guidelines for university libraries in Kenya. Available from: http://www.cue.or.ke/downloads/category/6-standards-andguidelines?download=35: standards-and-guidelines-for-universitylibraries-in-kenya. Accessed 23 January 2015.

Commission of University Education (2014). List of universities and colleges in Kenya. Available from: http://www.cue.or.ke/images/phocadownload/ACCREDITED_UNIVE RSITIES_IN_KENYA_August_2014.pdf. Accessed 6 November 2014.

DiNucci D, Guidice M, Stiles L (1999). The elements of web design. San Francisco: Peachpit Press.

Goh CM, Siew PL, Wei H, Puay ST (2007). Web 2.0. concepts and Technologies for dynamic B2B integration. Available from: http://ieeexplore.ieee.org/xpl/mostRecentlssue.jsp?punumber $=44167$ 42. Accessed 6 November 2014.

Gunasekara RM (2005). The role of the librarian of a research library: with relevant to field of agriculture. J. Uni. Libr. Assoc. Sri Lanka 9:62-69.

Hangsing P, Sinate L (2012). Use of Web 2.0 in academic libraries in India: a survey of central university library websites. Available from: http://www.lab.org.bd/4.pdf. Accessed 6 November 2014.

Huffman KD (2006). Web2.0: beyond the concept: practical ways to implement RSS. Web 2.0: beyond the concept: practical ways to implement RSS, podcast and wikis. Educ. Libr. 29(1):12-19.
Imran M (2011). Impact and application of Web 2.0 in libraries, a case study of the developed nations. Brazil J. Inform. Sci. 5(2):41-56.

Kebede $\mathrm{H}$ (2014). Adoption of Web 2.0 in academic libraries of top African universities. Elect. Libr. 32(2):262-277.

Kent A, Lancour H, Daily JE (1978). Encyclopedia of Library and Information Science. Danvers: CRC Press.

Khalid M (2013). Impact of Web 2.0 technologies on academic libraries: a survey of ARL libraries. Elect. Libr. 31(4):508-520.

Kiman M (1982). University of Nairobi Library System. Maktaba. 6(1):420.

Libraries and Social Software in Education (LASSIE) (2007). Libraries and social software in education project document. Available from: http://clt.Ise.ac.uk/Projects/LASSIE.php. Accessed on 10 September 2014.

Makori EO (2012). Bridging the information gap with the patrons in university libraries in Africa: the case for investments in Web 2.0 systems. Libr. Rev. 61(1):30-40.

McAfee A (2006). Enterprise 2.0: The Dawn of Emergent Collaboration. MIT Sloan Manage. Rev. 47(3):21-28. Available from: http://adamkcarson.files.wordpress.com/2006/12/enterprise_20__the_dawn_of_emergent_collaboration_by_andrew_mcafee.pdf. Accessed 6 November 2014.

Documentation for the National Center for Education Statistics (2010). Academic library survey: 2010first look. Available from: http://nces.ed.gov/pubs2012/2012365.pdf. Accessed 8 November 2014.

Neuman LW (2006). Social research methods: qualitative and quantitative approach. Boston: Pearson.

Otike J (2004). Development of libraries in Kenya. Available from: http://www.ku.ac.ke/schools/education/images/stories/research/devel opment-of-libraries-in-kenya.pdf. Accessed 6 November 2014.

O'Reilly T (2005). What is Web 2.0: design patterns and business models for the next generation of software. Available from: http://hbswk.hbs.edu/archive/5102.html. Accessed 8 November 2014.

Pachler N, Daly C (2009). Narrative and learning with Web 2.0 technologies towards a research agenda. J. Comput. Assisted Learn. 25(1):6-18.

Traue J (2009). From library to digital Disneyland. Available from: http://www.stuff.co.nz/blogs/opinion/2333070/From-library-to-digitalDisneyland. Accessed 8 November 2014. 